\title{
Relationship between altitude and lithium in groundwater in the United States of America: results of a 1992-2003 study
}

\author{
Rebekah S. Huber ${ }^{1}$, Namkug Kim ${ }^{1,2}$, Carl E. Renshaw ${ }^{3}$, Perry F. Renshaw ${ }^{1,4,5}$, Douglas G. \\ Kondo $^{1,4,5}$ \\ ${ }^{1}$ The Brain Institute, University of Utah, Salt Lake City, USA; ${ }^{2}$ Deparment of Radiology, Research Institute of \\ Radiology, University of Ulsan, College of Medicine, Seoul, South Korea; ${ }^{3}$ Department of Earth Sciences, \\ Dartmouth College, Hanover, USA; ${ }^{4}$ Department of Psychiatry, University of Utah, School of Medicine, Salt \\ Lake City, USA; ${ }^{5}$ VISN 19 Mental Illness Research, Education and Clinical Center, Veterans Affairs Medical \\ Center, Salt Lake City, USA
}

\begin{abstract}
Therapeutic dosages of lithium are known to reduce suicide rates, which has led to investigations of confounding environmental risk factors for suicide such as lithium in groundwater. It has been speculated that this might play a role in the potential relationship between suicide and altitude. A recent study in Austria involving geospatial analysis of lithium in groundwater and suicide found lower levels of lithium at higher altitudes. Since there is no reason to suspect this correlation is universal given variation in geology, the current study set out to investigate the relationship between altitude and lithium in groundwater in the United States of America (USA). The study utilised data extracted from the National Water-Quality Assessment programme implemented by the United States Geological Survey that has collected 5,183 samples from 48 study areas in USA for the period of 1992 to 2003. Lithium was the trace-element of interest and 518 samples were used in the current analyses. Due to uneven lithium sampling within the country, only the states $(n=15)$ with the highest number of lithium samples were included. Federal information processing standard codes were used to match data by county with the mean county altitude calculated using altitude data from the Shuttle Radar Topography Mission. The study was controlled for potential confounding factors known to affect levels of lithium in groundwater including aquifer, aquifer type, lithology, water level and the depths of wells. The levels of lithium in groundwater, increased with altitude $\left(\mathrm{R}^{2}=0.226, \mathrm{P}<0.001\right)$ during the study period. These findings differ from the Austrian study and suggest a need for further research accounting also for the impact of geographical variation.
\end{abstract}

Keywords: altitude, lithium, groundwater, suicide, United States of America.

\section{Background}

Suicide is a worldwide public health issue and recent studies have investigated environmental factors as a cause of geographic variation influencing local suicide rates. Interestingly, several studies have shown a relationship between altitude and suicide rates (Haws et al., 2009; Brenner et al., 2011; Kim et al., 2011). Kim et al. (2011) demonstrated that living at higher altitudes was associated with increased suicide rates, controlling for gun ownership, rural situations and mental health. Evaluating 2,584 counties in the United States of America (USA), Brenner and colleagues (2011) found that suicide rates significantly increase beginning at 2,000 ft $(610 \mathrm{~m})$ of residence. It has been sug-

Corresponding author:

Rebekah S. Huber

The Brain Institute, University of Utah

383 Colorow Drive, Salt Lake City, UT 84108, USA

Tel. +1 801-587-1439; Fax +1 801-585-0625

E-mail: rebekah.huber@utah.edu gested that the underlying mechanism could be hypobaric hypoxia, which can reduce brain serotonin levels thereby increasing depressive symptoms (Young, 2013).

It is well known that an association exists between therapeutic dosages of lithium and reduced suicide rates (Cipriani et al., 2005). However, the threshold lithium level, which conveys protection against suicide, remains unclear. The association between lithium and suicide rates has motivated several studies examining the effect of lithium in ground/drinking water and suicide mortality with mixed results. A few studies have shown a positive association between increased levels of lithium and lower rates of suicide (Ohgami et al., 2009; Kapusta et al., 2011; Bluml et al., 2013; Giotakos et al., 2013). In contrast, a study of 47 subdivisions in the east of England found no association between lithium in drinking water and suicide rates (Kabacs et al., 2011). It is unclear whether increased levels of lithium offer protective properties or if the efficacy of lithium is confounded by other environmental factors. 
Lithium, altitude and suicide

A study of lithium in healthy volunteers has demonstrated that altitude can change the pharmacokinetics of lithium (Arancibia et al., 2003). Volunteers were administered $300 \mathrm{mg}$ of lithium carbonate at $600 \mathrm{~m}$ above the mean sea level (MSL) at acute exposure (15 hours) and after chronic exposure (10 months) at 4,360 $\mathrm{m}$ above MSL. Results showed a $64.1 \%$ increase in elimination half-life for the acute exposure group and $111.4 \%$ increase for the chronic exposure group compared to the control group at MSL. This may be clinically relevant for lithium treatment of patients at higher altitudes. Increased elimination halflife of lithium with altitude would result in slower excretion of lithium and would also be consistent with a protective effect.

Lithium and altitude have been hypothesised to play a role in the geographic variation in the rates of suicide. A recent Austrian study investigated the relationship between suicide, lithium in ground water and altitude (Helbich et al., 2013). A spatial analysis was conducted, in which these investigators reported a negative association between lithium levels and altitude. Furthermore, they concluded that altitude moderates the impact of lithium effects on suicide mortality. Therefore the argument was put forth that altitude effects on suicide mortality may be a function of lithium contents in the drinking water. However, lithium is widely distributed in the Earth's crust and Helbrich et al. (2013) offer no discussion of a geologic process by which lithium is generally concentrated by lower altitudes.

\section{Lithium in groundwater}

The average daily intake of lithium for an adult ranges from 650 to $3,100 \mu \mathrm{g}$, while therapeutic dosages of lithium range from 900 to $1,200 \mathrm{mg} /$ day. The main sources of dietary intake of lithium are variable amounts in grains, vegetables and drinking water. The range of lithium in drinking water varies greatly by region and within environments (Schrauzer, 2002). In 2000 , groundwater accounted for about $46 \%$ of water used in USA, with about $31 \%$ used for public supply and $15 \%$ derived from private wells (Ayotte et al., 2011). The purpose of the present study was to investigate the relationship between lithium in groundwater and altitude in the USA, a country with strongly varied topography from the coastal plains to the Appalachian Mountains and from the Great Plains of the Midwest to the Intermountain West. The altitude ranges from 282 to $14,505 \mathrm{ft}(86-4,421 \mathrm{~m})$. Previous studies have examined the relationship between suicide and altitude due to geographic variation in suicide rates (Haws et al., 2009; Brenner et al., 2011; Kim et al., 2011). In contrast to previous findings in Austria (Helbich et al., 2013), we hypothesised that the tendency for higher levels of lithium in groundwater to occur at lower altitudes is not universal and would not necessarily be true within USA.

\section{Material and methods \\ Lithium in groundwater}

The present study utilised data from the National Water-Quality Assessment (NAWQA) Programme implemented by the United States Geological Survey (USGS). The USGS NAWQA Programme collected water samples from major aquifer groups in USA from 1992-2003 to evaluate trace-element concentrations in groundwater. Overall, the USGS study (USGS, 2001) collected 5,183 samples from 48 NAWQA study areas using the following approach: polyetrafluoroethylene tubing was connected to a submersible pump or a waterline. Wells were pumped until a stable water temperature, $\mathrm{pH}$ and specific conductance were reached. Groundwater samples were collected in a portable sampling chamber at a flow rate of $0.5 \mathrm{l} / \mathrm{min}$. Samples were passed through a $0.45-\mu \mathrm{m}$ disposable polypropylene capsule filter and samples were acidified to a $\mathrm{pH}$ of less than 2 with ultra-pure nitric acid. All samples were analysed using inductively-coupled plasma atomic-emission spectrometry (ICP-AES), inductively-coupled plasma mass spectrometry (ICPMS), graphite-furnace atomic-absorption spectrometry (AA) or hydride-generation atomic-absorption spectrometry at the National Water Quality Laboratory in Denver, CO, USA.

For the current study, lithium was the trace-element of interest. Currently, lithium does not have drinkingwater standards issued by the United States Environmental Protection Agency (EPA) (US EPA, 2009). Since climate and geology of aquifers have an important influence on the occurrence and distribution of trace-elements in groundwater, lithium was analysed in relation to these parameters as well as with regard to types of wells and well depths. In dry regions, samples from drinking water wells generally have greater concentrations of lithium (Ayotte et al., 2011). The majority of samples of lithium in the groundwater were concentrated in 15 different regions throughout the country. The level of lithium for each 
county was estimated by averaging all lithium samples from 1992 to 2003 across all stations. The lithium levels for each county in the 15 regions with the highest number of lithium samples were included in the present analysis. Fig. 1 displays these regions, which included states with more than 20 counties with lithium groundwater samples.

\section{Mean county altitude}

Mean county altitudes in this study were calculated using altitude data from the Shuttle Radar Topography Mission (SRTM) (available at http:// www2.jpl.nasa.gov/srtm/). Created in 2000, the SRTM is a digital topographical global scale of Earth with $0.1 \mathrm{~km}$ spatial resolution. The mean altitude of each county in the SRTM dataset was calculated using zonal statistics within the ArcGIS/ArcInfo 9.3 environment (ESRI; Redlands, USA). Data from all 48 states and the District of Columbia (D.C.) were used in the analyses. Alaska and Hawaii were not included because digital altitude information was not fully available in the STRM dataset. State outlines from the National Atlas of the United States (http://www.lib.vt.edu/find/databases/N/national-atlas-of-the-united-states.html) were used to obtain mean county altitudes based on SRTM mean elevation calculations for each $\mathrm{km}^{2}$.

Correlation analyses were conducted between levels of lithium in groundwater and the following variables to control for possible covariates: aquifer, aquifer type, lithology, water level and well depth. These variables have been shown to affect the level of lithium concentrations in ground water (Ayotte et al., 2011). Only variables, such as aquifer, water level and well depth, that significantly correlated with levels of lithium in groundwater were included in the model of lithium and altitude.

\section{Data analyses}

Multivariate linear regression analysis was used to investigate the relationship between altitude and lithium in the ground water. All analyses were conducted using Statistical Product and Service Solutions version 21 (SPSS) and statistical significance was defined at an alpha level of 0.05 .

\section{Results}

Results of the multivariate linear regression analysis demonstrated a significant relationship between mean county altitude and lithium in groundwater $(\mathrm{F}=23.31 ; \mathrm{P}<0.001)$. In this model, the adjusted $\mathrm{R}^{2}$ value was 0.216 , suggesting that altitude accounts for a modest proportion of the variance in regional variation in the amount of lithium in ground water. Table 1 displays results from the regression analysis. Water level was the only predictor variable significantly related to lithium $(\mathrm{B}=0.157 ; \mathrm{P}<0.001)$. Aquifer was significant at the trend level $(\mathrm{B}=-0.142 ; \mathrm{P}=0.054)$. Well

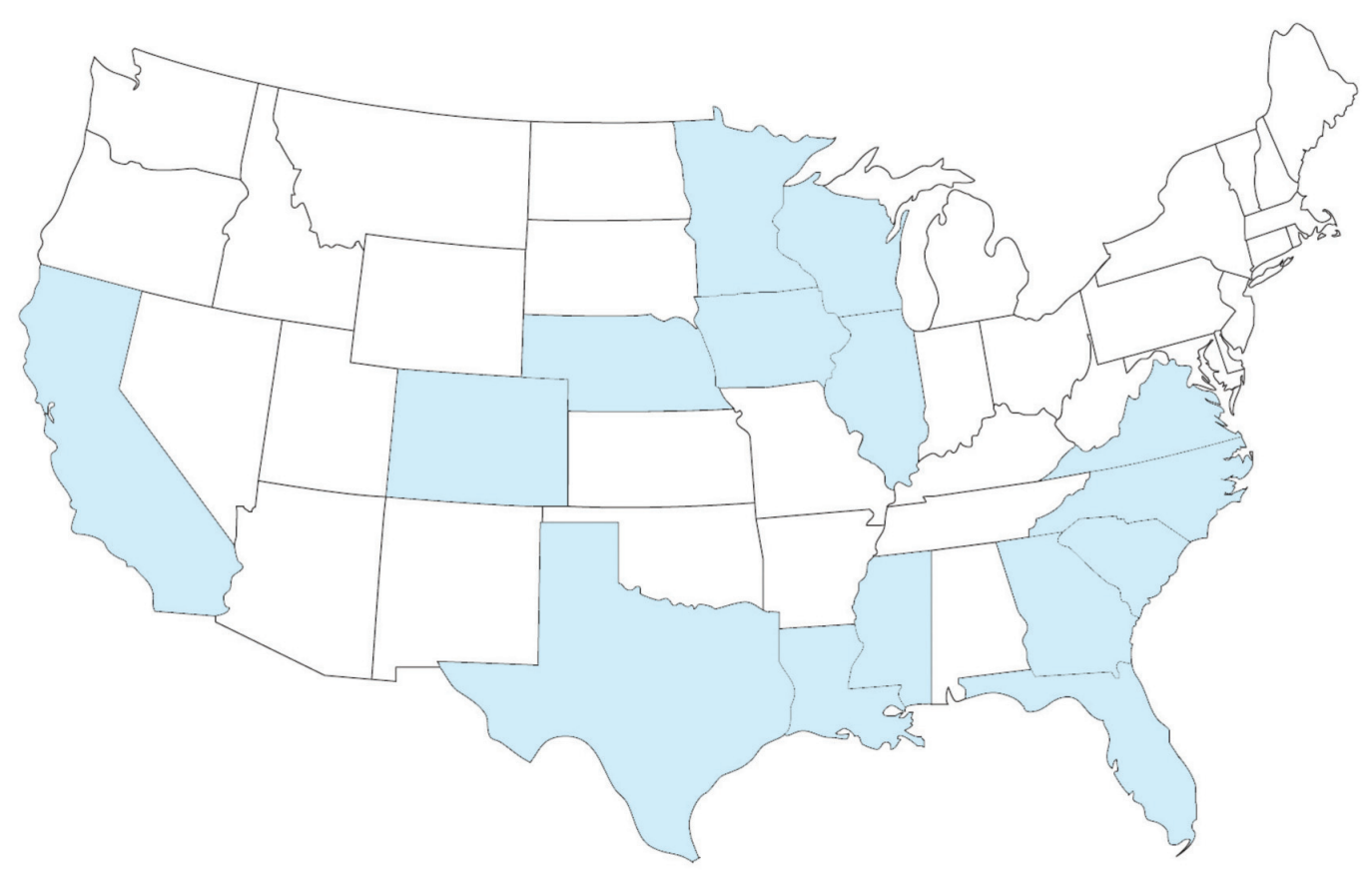

Fig. 1. The 15 states with the highest groundwater lithium concentrations in USA according to the USGS 1992-2003 study. 
Table 1. Multivariate linear regression analysis predicting levels of lithium in ground water in USA, 1992-2003.

\begin{tabular}{lcccc}
\hline Variables & $\mathrm{B}^{*}$ & $\mathrm{SE**}$ & $\mathrm{t}$ & $\mathrm{P}$ \\
\hline Intercept & 10.914 & 4.233 & 2.58 & 0.010 \\
Mean altitude & 0.009 & 0.003 & 2.61 & 0.009 \\
Aquifer & -0.142 & 0.073 & -1.93 & 0.054 \\
Water level & 0.157 & 0.023 & 6.88 & 0.000 \\
Well depth & 0.004 & 0.003 & 1.46 & 0.146 \\
\hline Model summary & $\mathrm{R}^{2}=0.226$ & Adjusted $\mathrm{R}^{2}=0.216$ & $\mathrm{~F}=23.31$ & $\mathrm{P}<0.001$
\end{tabular}

*regression coefficient; * *standard error.

depth was not was not a significant predictor of lithium levels in groundwater. These results can be used to define the following model:

Lithium in groundwater ${ }_{i}=$

$10.914+\left(0.009\right.$ altitude $\left._{i}\right)+\left(0.157\right.$ water level $\left._{i}\right)$

meaning that when altitude and water level of the water source increase, so do lithium levels in the groundwater.

\section{Discussion}

County-level data were used to investigate the hypothesis that altitude of residence is related to levels of lithium in groundwater in USA. Specifically, the current study aimed at replicating findings from a recent study conducted in Austria demonstrating that as altitude increases, levels of lithium decrease (Helbich et al., 2013). The present results do not support the generalisation of those findings. In fact, the opposite was found as it demonstrates that, over the range of aquifers considered here, lithium levels in groundwater increase with altitude and water level of the water source.

This is the first study to investigate the effects of altitude on the levels of lithium in groundwater in USA. The present results suggest that lithium and altitude may have a different relationship in the North American continent than has been reported in Austria. However, these findings should be interpreted with caution. The lithium samples used represent 518 American counties, while many counties were not included. There is a large amount of lithium concentration in certain regions in USA due to local climate, geology and lithology. Lithium concentrations often depend on the geology of aquifers and the distribution of groundwater. Higher lithium concentrations have been found in drinking water samples in dry climates
(Ayotte et al., 2011). Therefore, the American lithium concentrations may be more dependent on geology of aquifers, topography and climate than altitude.

Additionally, there are a smaller number of lithium samples collected at higher altitudes. Helbich and colleagues (2013) also noted this as a similar limitation of their study results. Several of the covariates of lithium levels in groundwater were tested, however, only the water level was found to be a significant predictor of lithium levels in the current model. The aquifer that groundwater originated from had moderate significance in predicting the levels of lithium. The strengths of the present study include the use of mean county level estimates of altitude and lithium levels in ground water. Furthermore, the study included large datasets from the USGS with lithium samples from on long period of time spanning 1992 to 2003.

\section{Conclusion}

Suicide is a worldwide health concern and identifying environmental risk factors such as altitude and lithium in groundwater is critical to improved suicide prevention efforts. Examination of USGS data revealed that the levels of lithium in groundwater increase with altitude in USA. These findings are dissimilar from recent research undertaken in Austria (Helbich et al., 2013) and suggest that more research is necessary to characterise the relationship between altitude, lithium and suicide.

\section{Acknowledgements}

This work was supported by the VISN 19 Mental Illness Research Education and Clinical Center (MIRECC), the Utah Science Technology and Research (USTAR) Initiative and DA031247. The views in this paper are those of the authors and do not necessarily represent the official policy or position of the Department of Veterans Affairs or the United States Government. 
Data for this study were made available through the USGS National Water Quality Assessment programme. The authors of this study do not have any commercial associations that might pose a conflict of interest in connection with this manuscript. The authors of this manuscript conducted all data analyses.

\section{References}

Arancibia A, Paulos C, Chavez J, Ritschel WA, 2003. Pharmacokinetics of lithium in healthy volunteers after exposure to high altitude. Int J Clin Pharmacol Ther 41, 200-206.

Ayotte JD, Gronberg JM, Apodaca LE, 2011. Trace elements and radon in groundwater across the United States, 19922003. U.S. Geological Survey Scientific Investigations Report 2011-5059, 115 p.

Bluml V, Regier MD, Hlavin G, Rockett IR, Konig F, Vyssoki B, Kapusta ND, 2013. Lithium in the public water supply and suicide mortality in Texas. J Psychiatr Res 47, 407-411.

Brenner B, Cheng D, Clark S, Camargo CA Jr, 2011. Positive association between altitude and suicide in 2584 U.S. counties. High Alt Med Biol 12, 31-35.

Cipriani A, Pretty H, Hawton K, Geddes JR, 2005. Lithium in the prevention of suicidal behavior and all-cause mortality in patients with mood disorders: a systematic review of randomized trials. Am J Psychiatry 162, 1805-1819.

Giotakos O, Nisianakis P, Tsouvelas G, Giakalou VV, 2013. Lithium in the public water supply and suicide mortality in Greece. Biol Trace Elem Res 156, 376-379.

Haws CA, Gray DD, Yurgelun-Todd DA, Moskos M, Meyer LJ,
Renshaw PF, 2009. The possible effect of altitude on regional variation in suicide rates. Med Hypotheses 73, 587-590.

Helbich M, Bluml V, Leitner M, Kapusta ND, 2013. Does altitude moderate the impact of lithium on suicide? A spatial analysis of Austria. Geospat Health 7, 209-218.

Kabacs N, Memon A, Obinwa T, Stochl J, Perez J, 2011. Lithium in drinking water and suicide rates across the East of England. Br J Psychiatry 198, 406-407.

Kapusta ND, Mossaheb N, Etzersdorfer E, Hlavin G, Thau K, Willeit M, Leithner-Dziubas K, 2011. Lithium in drinking water and suicide mortality. Br J Psychiatry 198, 346-350.

Kim N, Mickelson JB, Brenner BE, Haws CA, Yurgelun-Todd DA, Renshaw PF, 2011. Altitude, gun ownership, rural areas, and suicide. Am J Psychiatry 168, 49-54.

Ohgami H, Terao T, Shiotsuki I, Ishii N, Iwata N, 2009. Lithium levels in drinking water and risk of suicide. $\mathrm{Br} \mathrm{J}$ Psychiatry 194, 464-465.

Schrauzer G, 2002. Lithium: occurrence, dietary intakes, nutritional essentiality. J Am Coll Nutr 21, 14-21.

US EPA, 2009. 2009 edition of the drinking water standards and health advisories: U.S. Environmental Protection Agency Office of Water, EPA, 822-R-04-005, 12 pp.

USGS, US Geological Survey, 2001. U.S. Geological Survey database. Available at: http://water.usgs.gov/nawqa/data (accessed on November 2013).

Young S, 2013. Elevated incidence of suicide in people living at altitude, smokers and patients with chronic obstructive pulmonary disease and asthma: possible role of hypoxia causing decreased serotonin synthesis. J Psychiatry Neurosci 38, 423-426. 